\title{
Association Between CYP2D6 Gene Polymorphism and the Demand for Oxycodone Hydrochloride in Female Patients
}

\author{
Zhang Jin, Liu Baowen, Li Ningbo and Zhang Xianwei* \\ Department of Anesthesiology, Tongji Hospital, Tongji Medical College, China \\ *Corresponding author: Zhang Xianwei, Department of Anesthesiology, Tongji Hospital, Tongji Medical College, \\ Huazhong University of Science and Technology, Wuhan, China
}

\section{ARTICLE INFO}

Received: 慧 February 21, 2020

Published: 彗 March 03, 2020

Citation: Zhang J, Liu B, Li N, Zhang X. Association Between CYP2D6 Gene Polymorphism and the Demand for Oxycodone Hydrochloride in Female Patients. Biomed J Sci \& Tech Res 26(2)-2020. BJSTR. MS.ID.004317.

Keywords: Oxycodone Hydrochloride; CYP2D6; rs1135840, SNP, Postoperative Pain

\section{ABSTRACT}

Objective: Oxycodone hydrochloride has become the second largest prescription opioid drug worldwide. However, it is still unclear how to predict its effectiveness and safety. The aim of this study was to explore the association between CYP2D6 gene polymorphism and the demand for oxycodone hydrochloride within $48 \mathrm{~h}$ after operation in thoracic surgery patients, providing reference for future clinical precise usage of oxycodone hydrochloride.

Methods: A total of 115 patients (47 female and 68 male) scheduled to undergo thoracic surgery who accepted oxycodone hydrochloride intravenous patient-controlled analgesia (IPCA) for the first $48 \mathrm{~h}$ were recruited. Responses to quantitative sensory testing of pressure pain (sharp and acupuncture) were assessed, data related to postoperative analgesia implemented by acute pain serve (APS) team were screened, blood samples were processed for the collection of genomic DNA and genotype of rs1135840 was performed using the polymerase chain reaction-restriction fragment length (PCR-RFLP) method. Association analyses were performed via logistic regression analysis after adjusting for covariates such as age and body mass index.

Results: The total consumption of oxycodone hydrochloride within 48 hours after surgery by PCA was lower in female patients than in male patients $(p<0.05)$, as well as the consumption for per unit of body weight $(\mathrm{p}<0.05)$. The consumption and press frequency of PCA within $48 \mathrm{~h}$ of female patients were linearly correlated with rs 1135840 $(\mathrm{p}<0.05)$. The $\mathrm{CG}+\mathrm{GG}$ group had higher consumption and more frequency of oxycodone hydrochloride than the CC group $(6.941 \pm 1.549$ vs. $2.957 \pm 0.5846 ; 41.47 \pm 3.607$ vs. $31.35 \pm 2.111$, respectively, both $\mathrm{p}<0.05$ ).

Conclusion: This study suggests that CYP2D6 gene polymorphism is involved in the analgesic effect of oxycodone hydrochloride. The homozygote (CC)might reduce while the G allele and G carrier (CG+GG) of rs1135840 might increase the demand of oxycodone hydrochloride in female patients after thoracic surgery.

\section{Introduction}

Pain is one of the most common postoperative complications. A classic survey showed that among randomly selected postoperative patients, about $80 \%$ reported having suffered from acute postoperative pain, and $86 \%$ of them reported moderate or severe or even extreme pain [1]. Thoracic surgeries are one of the highest risk and most painful procedures. Clinical investigation found that despite improvements in aggressive perioperative analgesia, moderate to severe pain when coughing or moving was reported in over $85 \%$ of patients during the first two days [2], and the incidence of chronic pain after thoracic surgery was as high as $50 \%[3,4]$. Currently, postoperative analgesia methods in thoracic surgery mainly include Epidural Patient-Controlled Analgesia (EPCA), Intravenous Patient-Controlled Analgesia (IPCA), and so on. Opioids are the most powerful drugs against pain [5]. Oxycodone hydrochloride, a semisynthetic opioid analgesic, is widely used to treat moderate or severe cancer pain, neuropathic 
pain, acute postoperative pain and chronic nonmalignant pain [68]. Moreover, it is recommended for thoracic surgery because of its good effect on visceral pain. But its clinical analgesic effect is not satisfactory enough and why? The major reason may be individual differences, which can lead to differences in drug efficacy. In view of this, personalized medicine is one of the most promising solutions to increase the effectiveness and reduce the risk of side effect in patients' treatment [9].

In clinical practice, there are significant individual differences in the demand for oxycodone hydrochloride to relieve pain and the side effects, such as opioid receptors, transporter and metabolic enzyme. Indeed, the genetic polymorphism of CYP450 determines interindividual variability in the metabolism of many drugs, and significantly affecting the pharmacokinetics of about $50 \%$ of the drugs $[10,11]$. CYP2D6 is an important member of the CYP450 enzyme family in the liver. Although it only accounts for $2-4 \%$ of the total hepatic enzymes, it is involved in the metabolism of nearly $25 \%$ exogenous drugs [12]. CYP2D6 enzyme activity is highly variable because of single nucleotide polymorphisms (SNPs) and other alterations of the CYP2D6 gene [13].

Studies found that oxycodone hydrochloride is metabolized mainly via $\mathrm{N}$-demethylation by the CYP450 enzyme system, using CYP2D6 as one of the major pathways and producing active metabolite oxymorphone, which impacted its effectiveness and safety $[14,15]$. Among the numerous CYP2D6 alleles reported, those with full function, less function and null function were included [16]. Based on its substrate consumption efficiency, it can be divided into four types: ultra-rapid metabolism (UM), strong metabolism (EM), moderate metabolism (IM) and weak metabolism (PM) [17]. Rs1135840 (4180C>G, S486T) polymorphisms are responsible for CYP2D6 gene products with the UM phenotype [18]. As ultra-rapid CYP2D6 metabolizer's patients would need higher drug doses, they are more at risk to develop more side effects. Given that the allele frequency of rs 1135840 in healthy han population is 0.5735 , and it is endemic to asians. Therefore, preoperative screening of CYP2D6 gene polymorphism may predict postoperative analgesic effect and demand of oxycodone hydrochloride in patients. In recent years, the scientists have witnessed the increasing interest in genomics and pharmacogenetics as possible tools to predict the effectiveness and safety of pharmacological treatments. Nevertheless, there is no clear evidence of the role of genetic analysis in thoracic surgery patients with oxycodone hydrochloride. Hence, this study used gene sequencing technology to screen the CYP2D6 rs1135840 SNP and explore the association between the SNP and the oxycodone hydrochloride analgesic dose within $48 \mathrm{~h}$ post-operation in thoracic surgery patients, in order to guide the individualization of oxycodone hydrochloride clinical administration.

\section{Materials and Methods}

\section{Study Population}

The study protocol was approved by the Institutional Ethics Committee of Tongji Hospital, Tongji Medical College, Huazhong University of Science and Technology. All participants were informed of the purpose of the study, and informed written consent was obtained before commencement of the study. A total of 150 patients scheduled to undergo thoracic surgery who accepted oxycodone hydrochloride patient-controlled analgesia (PCA) for $48 \mathrm{~h}$ were recruited in Tongji Hospital, Tongji Medical College, Huazhong University of Science and Technology between August 1, 2017, and October 30, 2017.

\section{Inclusion criteria}

a) Age 18-70 y

b) ASA I-II

c) Conscious, and able to communicate normally

d) Right-handed and good test compliance to ensure its completion

\section{Exclusion criteria}

a) Long history of alcoholism and drug dependence

b) History of chronic pain and mental illness

c) Pain-related illness or use of analgesics within four weeks prior to the study

d) Medical diseases with poor control

e) Skin injury at the test site, which prevented the relevant test from being completed.

\section{Self-Rating Anxiety Scale (SAS) and Self-Rating Depression Scale (SDS) Assessment}

Before the self-assessment, the subject was expected to understand the entire scale and the meaning of each question, then based on the actual feeling of the last week, make an independent self-assessment that is not influenced by anyone. SAS and SDS consisted of 20 questions each, which were cored as 1-4 points, resulting in 20-80 raw score. Subsequently, standard score was calculated by int (1.25*raw score) and classified as: $25-49$, no anxiety/depression; 50-59, mild anxiety/depression; 60-69, moderate anxiety/depression; 70-100, severe anxiety/depression $[19,20]$.

\section{Mechanical Pain Sensitivity Measurements}

A hand-held electronic mechanical algometer (YISIDA-DS2, Hong Kong, China) was used to assess pressure pain sensitivity. Measurements were obtained using two different size probes and assessed on the right forearm at two sites in the following standardized sequential manner [21]: the midpoint of the dorsal region between the elbow and wrist, tested using a $0.1-\mathrm{cm} 2$ probe for sharp pressure pain threshold (S-PPT) and sharp pressure pain tolerance (S-PTO) measurements; and the midpoint of the medial and lateral borders of the wrist, tested using a $0.01-\mathrm{cm} 2$ probe for quantifying pricking pain (QPT). Subjects were instructed to say "pain" when they began to feel pain (S-PPT, or QPT), after 5 min stimulation restarted and the subjects were instructed to state "okay" when the pain became intolerable (S-PTO). This procedure was repeated $30 \mathrm{~min}$ later, and the average of the two assessments was calculated. 


\section{Collection and Storage of Blood Sample}

On the day of surgery, after creating central venous channel in the operating room, $2 \mathrm{ml}$ peripheral venous blood was collected in $5 \mathrm{ml}$ vacutainer tubes containing EDTA, labelled, and stored at -80 ${ }^{\circ} \mathrm{C}$.

\section{Analgesic Implementation}

Oxycodone hydrochloride analgesic pump was supplied by the acute pain serve (APS) team, anesthesiology department, Tongji hospital and connected to the patients as soon as possible after surgery. Besides, APS team needed to conduct postoperative visits to patients in accordance with the standard procedures, and made appropriate treatment based on the specific pain management, if the PCA was poor and the visual analogue scale (VAS) score at resting was higher than 40, additional analgesia measures were required and implemented by the APS team. We selected some of the data, which mainly included VAS scores at $6 \mathrm{~h}, 24 \mathrm{~h}$ and $48 \mathrm{~h}$ postoperatively, the consumption of oxycodone hydrochloride within $48 \mathrm{~h}$ post-operation, and side effects of the patients participating in this study. PCA formula: $0.2 \mathrm{mg} / \mathrm{ml}$ oxycodone hydrochloride hydrochloride $+0.04 \mathrm{mg} / \mathrm{ml}$ tropisetron, at a total volume of $175 \mathrm{ml}$. Body weight $40-50 \mathrm{~kg}$ : background dose: $1 \mathrm{ml} / \mathrm{h}$, press dose $1 \mathrm{ml} /$ time, locking time $10 \mathrm{~min}$, limited to $10 \mathrm{ml} / \mathrm{h}$; Body weight 50-60 kg: background dose $1.5 \mathrm{ml} / \mathrm{h}$, press dose $1.5 \mathrm{ml} /$ time, locking time $10 \mathrm{~min}$, limited to $12 \mathrm{ml} / \mathrm{h}$; Body weight 60-70 kg: background dose: $2 \mathrm{nl} / \mathrm{h}$, press dose $1.5 \mathrm{ml} /$ time, locking time
$10 \mathrm{~min}$, limited to $15 \mathrm{ml} / \mathrm{h}$; Body weight $>70 \mathrm{~kg}$ : background dose $2 \mathrm{ml} / \mathrm{h}$, press dose $2 \mathrm{ml} / \mathrm{h}$, locking time $10 \mathrm{~min}$, limited to $15 \mathrm{ml} / \mathrm{h}$.

\section{DNA Extraction and Genotyping}

Takara genome-wide DNA extraction kit was used to extract DNA from all blood samples, and the extracted DNA was stored at $-80{ }^{\circ} \mathrm{C}$ for later use. NCBI GenBank database was used to find the DNA sequence of CYP2D6 gene. Prime5 software was used to design amplified primers. The upstream primer was CTGCAGCACTTCAGCTTCTC, and the downstream primer was GGTACCCCATTCTAGCGGG. Primer synthesis and subsequent genotype identification were undertaken by Shanghai Yi He Applied Biotechnology Company using the polymerase chain reactionrestriction fragment length (PCR-RFLP) method.

\section{Statistical Analysis}

SPSS version 19.0 (SPSS Inc., Chicago, IL, USA) was used to process the data. The measurement data are shown as the mean \pm SD. The independent-sample t-test was used for comparison between the groups. Differences in enumeration data such as frequencies of number of patients with preoperative anxiety or depression, surgical category, and press times of PCA pump between the groups were analyzed using the chi-square test. Hardy-Weinberg Equilibrium (HWE) was also assessed by chi-square test. Genetic association analyses between rs1135840 and the PCA data was conducted using PLINK 1.07 [22]. P $<0.05$ was considered to be statistically significant.

\section{Results}

\section{Preliminary Analysis}

As shown in the overall flow diagram in Figure 1, we collected and analyzed the data from 115 patients, whose baseline characteristics are summarized in Table 1.

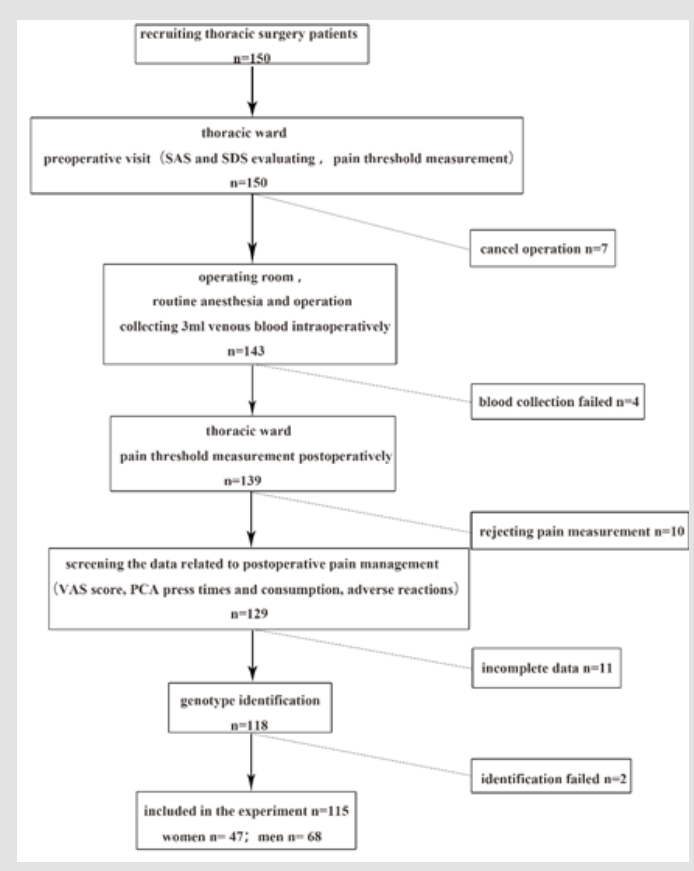

Figure 1: Flow diagram. Of the 150 patients, 35 withdrew due to surgery suspension, failure of collecting blood, rejecting pain measurement, incomplete data, and failure of genotyping. Thus, the sample consisted of 115 cases, including 68 men and 47 women. 
Table 1: Demographic and clinical characteristics of the study participants.

\begin{tabular}{|c|c|c|c|}
\hline & Female $\mathbf{n = 4 7}$ & Male $\mathbf{n = 6 8}$ & \multicolumn{1}{c|}{ P } \\
\hline Age(y) & $54.51 \pm 1.529$ & $56.65 \pm 0.963$ & 0.2166 \\
\hline BM(kg/m2) & $22.80 \pm 0.490$ & $22.93 \pm 0.339$ & 0.445 \\
\hline SAS & 2 mild, 1 moderate & 2 mild & 0.4814 \\
\hline SDS & 3mid, 1 moderate & 5 mild & 0.1109 \\
\hline thoracotomy/ & $10 / 32 / 5$ & $11 / 39 / 18$ & $0.0449^{*}$ \\
\hline $\begin{array}{c}\text { Endoscopic pneumonectomy/ } \\
\text { esophagectomy }\end{array}$ & $10.42 \pm 0.458$ & $11.86 \pm 0.488$ & $0.0126^{*}$ \\
\hline pre-PPT & $15.03 \pm 0.668$ & $17.34 \pm 0.601$ & $0.0240^{*}$ \\
\hline pre-PTO & $40.80 \pm 2.591$ & $48.78 \pm 2.303$ & $0.0002^{*}$ \\
\hline pre-QPT & $9.10 \pm 0.475$ & $11.71 \pm 0.441$ & $0.0002^{*}$ \\
\hline post-PPT & $12.50 \pm 0.553$ & $15.83 \pm 0.609$ & $0.0059^{*}$ \\
\hline post-PTO & $34.14 \pm 2.031$ & $42.95 \pm 2.194$ & 0.0876 \\
\hline post-QPT & $4.65 \pm 0.793$ & $6.97 \pm 0.934$ & $0.0005^{*}$ \\
\hline press frequency of PCA & $35.65 \pm 2.087$ & $50.25 \pm 2.921$ & $0.0437^{*}$ \\
\hline consumption of PCA & $0.64 \pm 0.036$ & $0.77 \pm 0.044$ & $0.0499^{*}$ \\
\hline consumption of PCA/weight & 7 & 3 & \\
\hline side effect & & & \\
\hline
\end{tabular}

BMI=body mass index; SAS, self-rating anxiety scale; SDS,self-rating depression scale; PPT,pressure pain threshold; PTO,pressure pain tolerance; QPT,quantifying pricking pain; pre,preoperative; post,postoperative; PCA, patient-controlled analgesia.

${ }^{*} \mathrm{p}<0.05$, with statistical difference.

The preoperative and postoperative pain thresholds of female patients were lower than that of male patients (all $p<0.05)$. The total consumption and the unit weight consumption of oxycodone hydrochloride within $48 \mathrm{~h}$ after surgery were lower in female patients than in male patients (all $\mathrm{p}<0.05)$.

Demographic data showed no statistical difference. The pain threshold of women was lower than that of men, the demand for

female patients than in male patients. ${ }^{*} \mathrm{p}<0.05$, with statistical oxycodone hydrochloride within $48 \mathrm{~h}$ after surgery was lower in difference.

Table 2: List of rs1135840 detected in total population, female, and male.

\begin{tabular}{|c|c|c|c|c|c|c|c|}
\hline SNP & Position & Minor Alleles & Major Alleles & Genotype counts & $\begin{array}{c}\text { Observed } \\
\text { heterozygosity }\end{array}$ & MAF & HWE p-value \\
\hline rs1135840 & $\begin{array}{c}\text { Chr22: } \\
42126611\end{array}$ & G & C & Total: $9 / 40 / 66$ & 0.348 & 0.258 & 0.404 \\
\hline & & & & Female: $4 / 18 / 25$ & 0.383 & 0.277 & 0.768 \\
\hline & & & & Male: $5 / 22 / 41$ & 0.324 & 0.236 & 0.405 \\
\hline
\end{tabular}

$\mathrm{SNP}=$ single nucleotide polymorphism; $\mathrm{MAF}=$ minor allele frequency; HWE $=$ Hardy-Weinberg equilibrium.

HWE $p>0.05$ means the group had good representativeness. 
Table 3: Linear regression-based association results for the demand of oxycodone hydrochloride and rs1135840 genotypes using the different model in female and male sample.

\begin{tabular}{|c|c|c|c|c|c|c|}
\hline Gender & PCA & SNP & $\beta$ & SE & $95 \% \mathrm{CI}$ & Statistics $(T, P)$ \\
\hline \multirow{6}{*}{ Female } & \multirow{3}{*}{$\begin{array}{c}\text { PCA } \\
\text { frequency }\end{array}$} & $\begin{array}{c}\text { CYP2D6 } \\
\text { rs1135840 (DOM) }\end{array}$ & 3.985 & 1.491 & $1.062-6.907$ & $2.672,0.011^{*}$ \\
\hline & & $\begin{array}{c}\text { CYP2D6 } \\
\text { rs1135840 (REC) }\end{array}$ & -1.556 & 2.666 & -10.451 & $-0.584, \quad 0.563$ \\
\hline & & $\begin{array}{c}\text { CYP2D6 } \\
\text { rs1135840 (ADD) }\end{array}$ & 1.855 & 1.16 & -4.547 & $1.599,0.118$ \\
\hline & \multirow{3}{*}{$\begin{array}{c}\text { PCA } \\
\text { consumption }\end{array}$} & $\begin{array}{c}\text { CYP2D6 } \\
\text { rs1135840 (DOM) }\end{array}$ & 10.12 & 3.949 & $2.382-17.860$ & $2.563,0.014^{*}$ \\
\hline & & $\begin{array}{c}\text { CYP2D6 } \\
\text { rs1135840 (REC) }\end{array}$ & -5.722 & 6.986 & -27.391 & $-0.819, \quad 0.418$ \\
\hline & & $\begin{array}{c}\text { CYP2D6 } \\
\text { rs1135840 (ADD) }\end{array}$ & 4.359 & 3.074 & -12.046 & $1.418,0.164$ \\
\hline \multirow{6}{*}{ Male } & \multirow{3}{*}{$\begin{array}{c}\text { PCA } \\
\text { frequency }\end{array}$} & $\begin{array}{c}\text { CYP2D6 } \\
\text { rs1135840(DOM) }\end{array}$ & -2.229 & 1.924 & -7.543 & $-1.158, \quad 0.251$ \\
\hline & & $\begin{array}{c}\text { CYP2D6 } \\
\text { rs1135840 (REC) }\end{array}$ & -2.837 & 3.541 & -13.881 & $-0.801,0.426$ \\
\hline & & $\begin{array}{c}\text { CYP2D6 } \\
\text { rs1135840 (ADD) }\end{array}$ & -1.827 & 1.481 & -5.806 & $-1.234, \quad 0.221$ \\
\hline & \multirow{3}{*}{$\begin{array}{c}\text { PCA } \\
\text { consumption }\end{array}$} & $\begin{array}{c}\text { CYP2D6 } \\
\text { rs1135840 (DOM) }\end{array}$ & -9.123 & 5.93 & -23.25 & $-1.538,0.129$ \\
\hline & & $\begin{array}{c}\text { CYP2D6 } \\
\text { rs1135840 (REC) }\end{array}$ & -12.59 & 10.94 & -52.76 & $0.333,0.741$ \\
\hline & & $\begin{array}{c}\text { CYP2D6 } \\
\text { rs1135840 (ADD) }\end{array}$ & -7.654 & 4.555 & -17.853 & $-1.680,0.098$ \\
\hline
\end{tabular}

Abbreviations: $\beta$, regression coefficient; SE, standard error; CI, confidence interval. DOM, dominant model; REC,recessive model; ADD, additive model.

${ }^{*} \mathrm{p}<0.05$, with statistical difference. In female patients, there was a linear regression correlation between the press frequency of PCA pump and the consumption of oxycodone hydrochloride with rs1135840 genotypes in dominant genetic model.

A

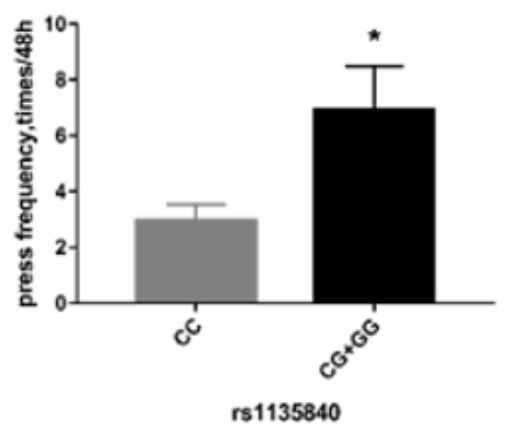

B

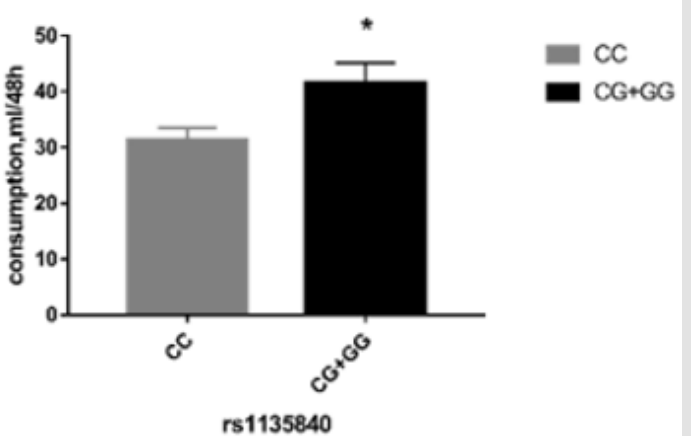

Figure 2: Comparison of oxycodone hydrochloride requirements between the CC and CG+GG groups in female patients. The press frequency and consumption of PCA within $48 \mathrm{~h}$ after operation of female patients were correlated with rs1135840. The CG+GG group had more times (A) and higher consumption (B) of oxycodone hydrochloride than the CC group ( $<<0.05)$.

\section{Association Between rs1135840 Genotypes and the Demand for Oxycodone Hydrochloride}

The HEW p values of men, women and total population were all greater than 0.05 ( $p>0.05)$, indicating that all groups had good representativeness (Table 2).

The press frequency and consumption of PCA pump within 48 $\mathrm{h}$ after thoracic surgery were correlated with linear regression of CYP2D6 gene polymorphism, and there were differences in dominant mode among female patients (Table 3 ).

Comparison of the demand for oxycodone hydrochloride within $48 \mathrm{~h}$ after surgery between different genotypes of rs1135840 in female patients (Figure 2). 


\section{Comparison of Other Indexes between the CC and CG+GG Groups in Female Patients}

There was no statistical difference in the preoperative and postoperative pain thresholds between rs1135840 genotypes in female patients (Table 4).

There was no statistical difference in VAS scores between rs1135840 genotypes at different time points after surgery among female patients (Table 5).

There was no statistical difference in the incidence of SAS, SDS and side effects between rs1135840 genotypes in female patients (Table 6). None of the patients suffered severe pain and therefore did not require additional analgesic measures. The side effects include dizziness, nausea, vomiting, but no respiratory depression.

Table 4: Comparison of pain thresholds between CC and CG+GG in female patients.

\begin{tabular}{|c|c|c|c|c|c|c|c|}
\hline Genotype & $\mathbf{n}$ & pre-PPT & pre-PTO & pre-QPT & post-PPT & post-PTO & post-QPT \\
\hline CC & 25 & $10.38 \pm 0.771$, & $15.11 \pm 0.973$, & $38.61 \pm 3.247$, & $8.59 \pm 0.603$, & $12.36 \pm 0.734$, & $31.96 \pm 3.006$ \\
\hline CG+GG & 22 & $10.77 \pm 0.697$, & $15.21 \pm 1.091$, & $42.90 \pm 4.029$, & $9.65 \pm 0.741$, & $12.68 \pm 0.860$, & $36.52 \pm 2.673$, \\
\hline t & & 0.365 & 0.067 & 0.837 & 1.114 & 0.282 & 1.127 \\
\hline p & & 0.716 & 0.947 & 0.407 & 0.272 & 0.779 & 0.266 \\
\hline
\end{tabular}

PPT, pressure pain threshold; PTO, pressure pain tolerance; QPT, quantifying pricking pain; pre, preoperative; post, postoperative.

There was no statistical difference in pain thresholds between the CC and CG+GG groups in female patients $(p>0.05)$.

Table 5: Comparison of VAS scores between the CC and CG+GG groups of female patients at different time points

\begin{tabular}{|c|c|c|c|c|c|c|c|}
\hline Genotype & $\mathbf{n}$ & VAS1-resting & VAS1-coughing & VAS2-resting & VAS2-coughing & VAS3-resting & VAS3-coughing \\
\hline $\mathrm{CC}$ & 25 & $9.33 \pm 0.667$ & $19.33 \pm 0.667$ & $8.75 \pm 0.689$ & $18.75 \pm 0.690$ & $9.47 \pm 1.203$ & $20.53 \pm 1.617$ \\
\hline $\mathrm{CG}+\mathrm{GG}$ & 22 & $9.29 \pm 0.714$ & $19.29 \pm 0.714$ & $6.25 \pm 1.250$ & $16.25 \pm 1.250$ & $7.65 \pm 1.611$ & $17.65 \pm 1.611$ \\
\hline $\mathrm{t}$ & & $\mathrm{t}=0.049$ & $\mathrm{t}=0.049$ & $\mathrm{t}=1.89$ & $\mathrm{t}=1.89$ & $\mathrm{t}=0.921$ & $\mathrm{t}=1.257$ \\
\hline $\mathrm{p}$ & & 0.961 & 0.961 & 0.066 & 0.066 & 0.364 & 0.217 \\
\hline
\end{tabular}

VAS, visual analogue scale; VAS1 $=6 \mathrm{~h}$ after surgery; VAS2=24 h after surgery; VAS3=48 h after surgery.

There was no statistical difference in VAS scores between the CC and CG+GG groups at different time points among female patients $(\mathrm{p}>0.05)$.

Table 6: Comparison of SAS, SDS, and side effects between the CC and CG+GG groups of female patients

\begin{tabular}{|c|c|c|c|c|c|c|}
\hline Item & Rank & $\mathbf{n}$ & Genotype & & $\mathrm{X} 2$ & $\mathbf{P}$ \\
\hline & & & $\mathrm{CC}$ & $\mathrm{CG}+\mathrm{GG}$ & & \\
\hline \multirow[t]{3}{*}{ SAS } & 0 & 44 & 23 & 21 & 2.942 & 0.2297 \\
\hline & 1 & 2 & 2 & 0 & & \\
\hline & 2 & 1 & 0 & 1 & & \\
\hline \multirow[t]{3}{*}{ SDS } & 0 & 43 & 23 & 20 & 1.357 & 0.5075 \\
\hline & 1 & 3 & 2 & 1 & & \\
\hline & 2 & 1 & 0 & 1 & & \\
\hline \multirow[t]{2}{*}{ side effect } & normal & 40 & 21 & 19 & 0.052 & 0.8203 \\
\hline & other & 7 & 4 & 3 & & \\
\hline
\end{tabular}

SAS, self-rating anxiety scale; SDS,self-rating depression scale.

There was no statistical difference in the incidence of SAS, SDS and side effects between the CC and CG+GG groups of female patients $(\mathrm{p}>0.05)$.

\section{Discussion}

Our study shows that the preoperative basal pain threshold (PPT, PTO, QPT) of women was lower than that of men, which is consistent with previous studies $[23,24]$. As we showed above, the usage frequency of PCA pump within $48 \mathrm{~h}$ after surgery of female patients was less than that of male patients. The consumption of total or per unit of body weight for oxycodone hydrochloride within $48 \mathrm{~h}$ of female patients were significantly lower than that of male patients. On the other hand, quantitative sensory testing of pressure pain was conducted on patients before and after surgery for objective assessment of experimental pain, and VAS scores at different time points after surgery were used as subjective assessment of postoperative pain. We found no difference in pressure pain threshold between men and women before and after surgery, and no difference in VAS scores at each time point after surgery. This suggested that to achieve the same analgesic effect, 
female patients had less need for oxycodone hydrochloride than male patients. Hence, women are more sensitive to oxycodone hydrochloride than men. Pre-clinical and clinical studies examining gender differences in morphine analgesia are inconsistent. Findings of greater analgesia in men versus women, women versus men, or no gender differences following opioid administration have been reported [25,26]. A study on pharmacokinetic parameters of oral administration of a single dose $(20 \mathrm{mg}$ ) of controlledrelease oxycodone hydrochloride in healthy subjects showed no significant differences between women and men in the area under the curve (AUC) and in peak plasma concentration (Cmax) related to oxycodone hydrochloride [27]. A significant difference between genders was found in both subjective and objective pharmacodynamic variables, women reported a greater feeling of opioid effects and more adverse reactions than men. Our study indicated that the demand of oxycodone hydrochloride after thoracic surgery was lower in women than in men, which could avoid the conventional wisdom that women are more sensitive to pain and therefore need more analgesics. This will provide new evidence for the individualized analgesic treatment of oxycodone hydrochloride. As to the reasons for gender difference, previous studies have shown that women's oxycodone hydrochloride elimination rate is $25 \%$ slower than that of men $[8,28]$, which may be due to women's water content being $15 \%$ higher than that of men. Based on the sex differences, we analyzed women and men separately.

Next, we conducted linear regression analysis for men and women. The usage frequency and consumption of PCA within $48 \mathrm{~h}$ after operation were used as dependent variables, and the genotype of polymorphic site rs1135840 of CYP2D6 gene was used as independent variable. The allelic frequencies of rs1135840 was consistent with Hardy-Weinberg equilibrium ( $p$ > 0.05) as shown in Table 2. The highly polymorphic CYP2D6 is one of the most studied genes in the cytochrome P450 family. Polymorphic site rs1135840 was genotyped and analyzed for its frequency in 47 women and 68 men, respectively. Linear regression analysis in Table 3 manifested that the usage frequency and consumption of PCA within $48 \mathrm{~h}$ after operation of female patients were correlated with rs1135840 in dominant inheritance pattern (dominant inheritance pattern: C as stealth allele, G as the dominant allele, carrying the CG and GG showed the same traits, so we compared and analyzed CC with $\mathrm{CG}+\mathrm{GG})$. As we know, the polymorphic site of $\mathrm{rs} 1135840(\mathrm{C}>\mathrm{G})$ is related to the UM of CYP2D6 enzyme. Drug metabolism is faster and drug demand is higher in patients carrying G allele of rs1135840.

Consistently, in this study, the CG+GG group had more times and higher consumption of oxycodone hydrochloride than the CC group among female patients. In addition, there were no differences in preoperative pain threshold, SAS, SDS, postoperative pain threshold, VAS, and side effects between the CG+GG and CC groups of female patients. Combined with the above, we found that in order to achieve the same analgesic effect in female patients after thoracic surgery, oxycodone hydrochloride analgesic dose in the $\mathrm{CG}+\mathrm{GG}$ group was higher than that in the CC group, which had certain predictive significance for the parameter setting of PCA after thoracic surgery in female patients. This study had some limitations. First, the sample size was relatively small, and was not verified in another population. Second, there are various factors that affect drug individualization. Opioid receptors, transporters and other CYP enzyme families can all affect the metabolism of oxycodone hydrochloride. Our study only focused on rs1135840, a polymorphic site of CYP2D6 gene, which can only explain part of the individualization of oxycodone hydrochloride in women, and the other factors still need to be further investigated.

\section{Conclusion}

This study suggests that CYP2D6 gene polymorphism is involved in the analgesic effect of oxycodone hydrochloride. The homozygote (CC)might reduce while the G allele and G carrier $(\mathrm{CG}+\mathrm{GG})$ of rs1135840 might increase the demand of oxycodone hydrochloride in female patients after thoracic surgery, which will provide reference for future clinical application of oxycodone hydrochloride.

\section{References}

1. Chapman CR, CJVierck (2017) The Transition of Acute Postoperative Pain to Chronic Pain: An Integrative Overview of Research on Mechanisms. J Pain 18(4): 359e1-359e38.

2. Wang H, Li S, Liang N, Liu W, Liu H, et al. (2017) Postoperative pain experiences in Chinese adult patients after thoracotomy and videoassisted thoracic surgery. J Clin Nurs 26(17-18): 2744-2754.

3. Song JG, Jin Woo Shin, Eun Ho Lee, Dae Kee Choi, Ji Youn Bang, et al. (2012) Incidence of post-thoracotomy pain: a comparison between total intravenous anaesthesia and inhalation anaesthesia. Eur J Cardiothorac Surg 41(5): 1078-1082.

4. Buchheit T, S Pyati (2012) Prevention of chronic pain after surgical nerve injury: amputation and thoracotomy. Surg Clin North Am 92(2): 393-407.

5. Kieffer BL (2016) Drug discovery: Designing the ideal opioid. Nature 537(7619): 170-171.

6. Leow KP, T Cramond, MT Smith (1995) Pharmacokinetics and pharmacodynamics of oxycodone when given intravenously and rectally to adult patients with cancer pain. Anesth Analg 80(2): 296-302.

7. Sindrup SH, TS Jensen (1999) Efficacy of pharmacological treatments of neuropathic pain: an update and effect related to mechanism of drug action. Pain 83(3): 389-400.

8. Kalso E (2005) Oxycodone. J Pain Symptom Manage 29(5 Suppl): S47-S56.

9. Akhondzadeh S (2014) Personalized medicine: a tailor-made medicine. Avicenna J Med Biotechnol 6(4): 191.

10. Cavallari LH, H Jeong, A Bress (2011) Role of cytochrome P450 genotype in the steps toward personalized drug therapy. Pharmgenomics Pers Med 4: 123-36.

11. Choi SW, Lam David MH, Wong Stanley SC, Shiu Haydn HC, Wang Amy XM, et al. (2017) Effects of Single Nucleotide Polymorphisms on Surgical and Postsurgical Opioid Requirements: A Systematic Review and MetaAnalysis. Clin J Pain 33(12): 1117-1130.

12. Ingelman Sundberg M, Sim SC, Gomez A, Rodriguez-Antona C (2007) Influence of cytochrome $\mathrm{P} 450$ polymorphisms on drug therapies: pharmacogenetic, pharmacoepigenetic and clinical aspects. Pharmacol Ther 116(3): 496-526.

13. Crews KR, Gaedigk A, Dunnenberger H, Leeder JS, Klein TE, et al. (2014) Clinical Pharmacogenetics Implementation Consortium guidelines for cytochrome P450 2D6 genotype and codeine therapy: 2014 update. Clin Pharmacol Ther 95(4): 376-82. 
14. Pergolizzi JJ, Seow Choen F, Wexner SD, Zampogna G, Raffa RB, et al. (2016) Perspectives on Intravenous Oxycodone for Control of Postoperative Pain. Pain Pract 16(7): 924-934.

15. Chang KL, K Weitzel, S Schmidt (2015) Pharmacogenetics: Using Genetic Information to Guide Drug Therapy. Am Fam Physician 92(7): 588-594.

16. Kitada M (2003) Genetic polymorphism of cytochrome P450 enzymes in Asian populations: focus on CYP2D6. Int J Clin Pharmacol Res 23(1): 31-35.

17. Zhou SF (2009) Polymorphism of human cytochrome P450 2D6 and its clinical significance: part II. Clin Pharmacokinet 48(12): 761-804.

18. Ahmed S, Zhou Z, Zhou J, Chen SQ (2016) Pharmacogenomics of Drug Metabolizing Enzymes and Transporters: Relevance to Precision Medicine. Genomics Proteomics Bioinformatics 14(5): 298-313.

19. Li H, Jin D, Qiao F, Chen J, Gong J, et al. (2016) Relationship between the Self-Rating Anxiety Scale score and the success rate of 64-slice computed tomography coronary angiography. Int J Psychiatry Med 51(1): 47-55.

20. Dunstan DA, N Scott, AK Todd (2017) Screening for anxiety and depression: reassessing the utility of the Zung scales. BMC Psychiatry 17(1): 329

21. Duan G, Xiang G, Zhang X, Guo S, Zhang Y, et al. (2014) An improvement of mechanical pain sensitivity measurement method: the smaller sized probes may detect heterogeneous sensory threshold in healthy male subjects. Pain Med 15(2): 272-280.

\section{ISSN: 2574-1241}

DOI: 10.26717/BJSTR.2020.26.004317

Zhang Xianwei. Biomed J Sci \& Tech Res

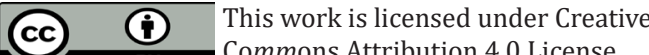

Submission Link: https://biomedres.us/submit-manuscript.php
22. Purcell S (2007) PLINK: a tool set for whole-genome association and population-based linkage analyses. Am J Hum Genet 81(3): 559-575.

23. Olesen AE (2017) Genetic variation in opioid receptor genes and sensitivity to experimental pain in male and female healthy volunteers. Scand J Pain 3(3): 193.

24. Sato H, Droney J, Ross J, Olesen AE, Staahl C, et al. (2013) Gender, variation in opioid receptor genes and sensitivity to experimental pain. Mol Pain 9: 20.

25. Cepeda MS, DB Carr (2003) Women experience more pain and require more morphine than men to achieve a similar degree of analgesia. Anesth Analg 97(5): 1464-1468.

26. Fillingim RB, Ness TJ, Glover TL, Campbell CM, Hastie BA, et al. (2005) Morphine responses and experimental pain: sex differences in side effects and cardiovascular responses but not analgesia. J Pain 6(2): 11624.

27. Kaiko RF, Benziger DP, Fitzmartin RD, Burke BE, Reder RF, et al. (1996) Pharmacokinetic-pharmacodynamic relationships of controlled-release oxycodone. Clin Pharmacol Ther 59(1): 52-61.

28. Liukas, A., K Kuusniemi, R Aantaa, P Virolainen, M Neuvonenet al. (2008) Plasma concentrations of oral oxycodone are greatly increased in the elderly. Clin Pharmacol Ther 84(4): 462-467.

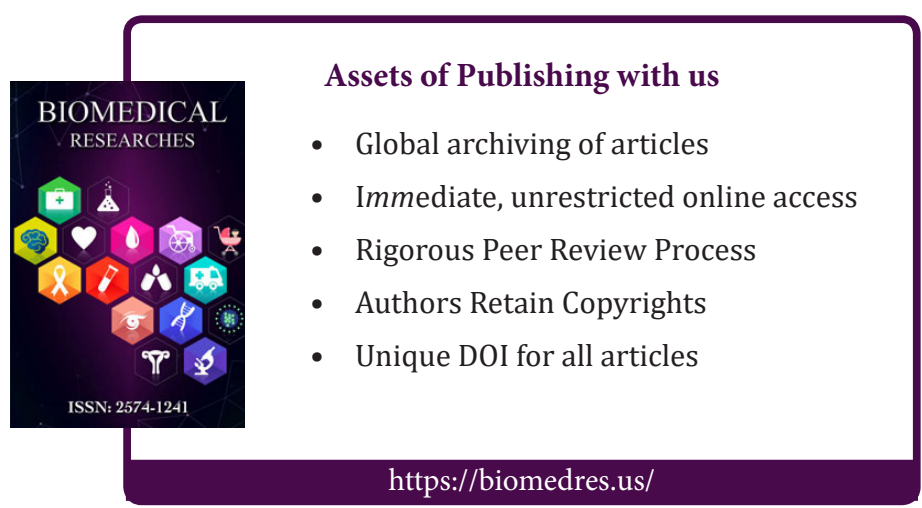

